\title{
Popperbate: Video Collage, Vernacular Creativity and the Scripting of the Gay Pornographic Body
}

\begin{tabular}{|c|c|}
\hline Journal: & Porn Studies \\
\hline Manuscript ID & RPRN-2017-0001.R1 \\
\hline Manuscript Type: & Original Paper \\
\hline Keywords: & $\begin{array}{l}\text { gay porn, amateur porn, scripting, video collage, productive leisure, } \\
\text { neoliberalism, popperbate }\end{array}$ \\
\hline Abstract: & $\begin{array}{l}\text { In this essay I explore the contemporary amateur practice of making } \\
\text { 'popper training' videos. These examples of amateur gay porn, usually } \\
\text { circulated via porn aggregators such as Xtube constitute what might be } \\
\text { described as video collages that repurpose a range of found sources } \\
\text { including commercial moving image gay porn to still images to text and } \\
\text { music. The resulting videos are designed for the express purpose of aiding } \\
\text { a form of masturbation often described as 'edging', fuelled by amyl nitrate } \\
\text { use, into a pursuit that is elevated to the status of a competitive training } \\
\text { activity, known by its practitioners as 'popperbating'. I argue that these } \\
\text { popperbate videos, that function as examples of what Jean Burgess has } \\
\text { described as 'vernacular creativity', construct masturbation as an activity } \\
\text { that might be regarded, as 'productive leisure'. The intention of this essay } \\
\text { is then to contextualise this creative practice, and to provide some } \\
\text { tentative conceptual orientations to situate popperbate videos, for the } \\
\text { analysis of the textual qualities of the videos, and to discuss the sexual } \\
\text { scripting that they produce. }\end{array}$ \\
\hline
\end{tabular}

\section{SCHOLARONE \\ Manuscripts}




\title{
Popperbate: Video Collage, Vernacular Creativity and the Scripting of the Gay
} Pornographic Body

\begin{abstract}
In this essay I explore the contemporary amateur practice of making 'popper training' videos. These examples of amateur gay porn, usually circulated via porn aggregators such as Xtube constitute what might be described as video collages that repurpose a range of found sources including commercial moving image gay porn to still images to text and music. The resulting videos are designed for the express purpose of aiding a form of masturbation often described as 'edging', fuelled by amyl nitrate use, into a pursuit that is elevated to the status of a competitive training activity, known by its practitioners as 'popperbating'. I argue that these popperbate videos, that function as examples of what Jean Burgess has described as 'vernacular creativity', construct masturbation as an activity that might be regarded, as 'productive leisure'. The intention of this essay is then to contextualise this creative practice, and to provide some tentative conceptual orientations to situate popperbate videos, for the analysis of the textual qualities of the videos, and to discuss the sexual scripting that they produce.
\end{abstract}

\section{Keywords: Gay pornography, amateur porn, sexual scripting, video collage, productive} leisure, neoliberalism, popperbating

\author{
Hello bator, \\ Let's train your cock, \\ Prepare you poppers, lube, cockring and put the sound high volume, \\ Inhale poppers on: HIT \\ Hold breath on: HOLD \\ Exhale breath on: RELEASE \\ BEGIN \\ PREPARE FOR A HIT \\ $3,2,1$, \\ HIT (for 7 seconds) \\ HOLD (for 5 seconds) \\ RELEASE
}

The precisely scripted list of instructions reproduced above, appear as text, superimposed over a pulsating montage of still and moving images of nude, sexually aroused men, engaging in a range of sexual acts progressing from frottage to anal sex, accompanied by a throbbing electronic dance track, that makes up the first 90 seconds of a 16-minute video piece entitled Popper Trainer Compilation Megapopperbator 01/04/2016 ${ }^{\mathrm{i}}$. As with the majority of ostensibly anonymous content of indeterminate provenance, uploaded to the web, the 
question of attribution means that porn researchers find themselves forced to make inferences about the material that becomes an object of study in a context such as this essay. So what assumptions is it fair to make about this specific cultural artefact?

In the first instance, we can confidently infer that the author of, what I will describe in this essay as, a video collage is an individual going by the online identity of Megapopperbator. Secondly, we might go on to suggest, given the platforms through which this material is distributed, the textual qualities of the collage and the level of technical proficiency evinced, that the video is an example of amateur porn production that illustrates what Jean Burgess (2006) has described as 'vernacular creativity.' Indeed, in many regards, as we will note later on in this essay we might argue that this form of cultural production is an especially vivid illustration of Burgess concept as she notes that;

'vernacular creativity', then, does not imply the reinvigoration of some notion of a pre-existing 'pure' or authentic folk culture placed in opposition to the mass media; rather, it includes as part of the contemporary vernacular the experience of commercial popular culture. Vernacular creativity is a productive articulation of consumer practices and knowledges (of, say, television genre codes) with older popular traditions and communicative practices (storytelling, family photography, scrapbooking, collecting). (ibid 206/7)

And thirdly, we can also safely assume, based on the large number of similar videos that have begun to emerge across a range of tube sites and associated discussion fora, that 'popperbating' and popperbate videos are a relatively popular, recent development in the pornosphere. $^{\text {ii }}$

Like much of contemporary sexual culture, and like so many of the constituent parts of popular culture more generally, the act of naming has brought a relatively prosaic, commonplace activity, in this case using amyl nitrate (poppers) as a stimulant during masturbation sessions (which in itself is far from a novel activity) into view as a distinct category of sexual conduct requiring specific competences and accoutrements, comprising a set of orthodoxies, and attracting a group of practitioners who proselytise the virtues of the practice. Popperbating as a sexual practice, and the centrality of porn to this activity, is usefully summarised through the unlikely medium of Craigslist personals where a poster in Columbus Ohio who adopts the online pseudonym, Popperbate, succinctly describes the practice and the sexual culture:

I am most likely watching some porn and lubing up my dick right now. I love stroking my dick and watching porn. I like to sniff poppers and jerk my cock to the edge and then back off. doing it over and over, enjoying the feeling of my cock riding a wave of pure pleasure. Until I can't hold back and need to release. I am looking for a good looking masculine fit buddy who shares the same interest in jerking and watching someone jerk. [...] Looking for a high-volume jizz producer to hose down my torso. Cock size much less important the size of the load you can spurt over me - chronic masturbators, saved-up loads, big shooters a big plus. Get back to me if you are interested. (http://columbus.craigslist.org/m4m/5829609516.html)

This is an essay then about the practice of making collage 'popper training' videos repurposing a range of found sources, from still images to amateur video and webcam 
footage to extracts from commercial gay porn, with the express purpose of turning masturbation, fuelled by amyl nitrate use, into an activity that might be regarded, as either 'productive leisure' (Gelber, 1999:2) or using Stephen Stebbins terminology 'serious leisure' (1992:2). Regardless of the phraseology here, this is a cultural practice and mode of production and consumption that can be framed within a wider set of debates around subjectivity and the state under Neoliberalism, where, as Rosenberg observes;

[...] the state is increasingly reluctant to govern, the most pressing obligation a citizen has to society is to 'empower' him- or herself privately. [...] Productive serious leisure practitioners $[\ldots]$ offer models of neoliberal citizenship and examples of enterprising citizens. (2011: 174-176)

The intention of this essay is to contextualise this creative practice of (what I am describing for the sake of simplicity and consistency as) popperbate or popper training video making rather than to comment in any length on the sexual practice itself or on the many examples of videos which document the practice in action, ${ }^{\text {iii }}$ to provide some conceptual orientations to situate the materials and for the analysis of the textual qualities of the videos, and to discuss the sexual scripting that they produce.

I choose the term scripting very deliberately here as it both has purchase as a term that is widely used in the sociological studies of sex and sexuality drawing, as it does, on the symbolic interactionism of Erving Goffman. Scripting is a particularly useful metaphor for thinking about the ways in which the production practices in evidence in online popper training videos connect to the emergence of a popperbating 'practice.' In The Presentation of Self Everyday Life, (1956) what has become known as Goffman's 'dramaturgical metaphor' of the cultural script, and his foregrounding of the importance of 'expressiveness' and 'dramatic realization' of everyday life has been profoundly influential on subsequent scholarship particularly in the field of sexology. William Simon and John Gagnon for instance, used the same metaphor in the foundational study Sexual Conduct (1973) with their development of sexual script theory. In a later paper 'Sexual scripts: Permanence and Change' in which they revisit the basis of their concept they describe scripting thus:

Scripts are essentially a metaphor for conceptualizing the production of behaviour within social life. Most of social life most of the time must operate under the guidance of an operating syntax, much as language is a precondition for speech. For behaviour to occur, something resembling scripting must occur on three distinct levels: cultural scenarios, interpersonal scripts, and intrapsychic scripts. (1986: 98)

More recently Jeffrey Escoffier has referenced Simon and Gagnon's sexual script theory drawing on this model in his own, albeit rather more instrumental, analysis of commercial gay porn and its contexts of production that is augmented by a range of interesting interviews with porn professionals. Escoffier identifies that sexual scripts are socially (and I would argue that for my purposes here they also are culturally) constructed:

Thus in Gagnon and Simon's view, everyday sexual scripts incorporate informal guidelines, rules and social norms governing sexual conduct [...] Such scripts take into account the participants, their personal and social qualities, their implied motives, and various behavioural cues. Scripts help organize a sequence of verbal and nonverbal activities that produce sexual experiences for its participants. (2007:62) 
In the case of the material that is my object of study in this essay, scripting provides a framework for identifying and conceptualising a set of discursive and representational strategies that make meaning at three interconnected levels.

Scripting sexual representations: The formalising and conventionalising of a set of sexual activities as they are represented via the process of isolation and selection that is inherent in the video editing process. This is in effect the production of what I've described elsewhere as a 'demotic idiom' (Mercer, 2017) of gay porn.

Describing/producing a sexual script: What emerges from these representational strategies is a gay sexual script or, perhaps more accurately, a gay pornographic sexual script, where one activity leads inevitably to another in a relatively linear fashion.

Scripting the sexualised masculine body of gay porn: This third level of scripting is especially important for me here. The representational strategies in evidence here as elsewhere across gay pornography, commercial, amateur or otherwise produces the male body as a sexual spectacle that is to be read in circumscribed (and therefore scripted) ways. Writing about the black masculine body in popular culture, for example, Ronald Jackson discusses the processes by which scripting of the body takes place:

Scripting refers to the assignment of bodies, as understood by the scripter (e.g., the media), to certain locations of being, followed by a sociopolitical value-assessment of those bodies based on how well they match the script imposed on them. [...] the cultural norms, values, traditions, expectations, and behavioural codes of the newly introduced text are irrespective of those intrinsic textual properties that were already present. (2006:54)

\section{Amateur Porn and Practices of Making}

The rather amorphous category of amateur porn has been written about quite extensively and continues to grow as an area of interest for scholars in the field (Attwood 2007, Van Doorn 2010, Paasonen 2010, 2011, 2014, Zecca 2014, Hofer 2014, Ruberg 2016, Mercer 2017). This breadth of critical interventions has brought a complex set of activities, texts, relations and interactions into view that have challenged simplistic assumptions about what amateur porn might be, exploring the textures of amateur aesthetics, the representational strategies of amateur porn makers, the connections between amateurism and ethical porn practices, as well as the emancipatory potentials that amateur porn offers, by responding to debates around inclusivity through representation of a plethora of social and subcultural groups, body types, ethnicities, genders and generations. Much of this scholarly work is predicated on a distinctions being drawn between professional, commercial, material produced by a putative homogenous industry and the diversity and heterogeneity of amateur production practices. These categories though, as Susanna Paasonen (2014:33) notes, are not necessarily so easy to unpick. Indeed, in an online industrial context that has resulted in huge structural change for the porn industry there are many instances where the distinctions between amateur and professional are increasingly largely arbitrary. Mindful of this proviso, amateur is nonetheless still a useful heuristic device for demarcating a field of production that seems to elude or challenge at least some commercial formal and generic imperatives. 
Within this rich amateur ecology, (and I am firmly situating popperbate videos within this domain) I am identifying yet another production practice that yields results that are qualitatively different from much of the material that has previously been written about. ${ }^{\text {iv }} \mathrm{I}$ am mindful that popperbating is, ostensibly, a relatively obscure cultural practice and that the adjunct to this activity, the popper training videos that I am discussing here are an equally specialised and singular mode of amateur production. However, it is perhaps this particularity that motivates this intervention in a consideration of what gay porn now means in terms of thinking about what results from an amateur making practice and conditions of production and consumption where distinctions between amateur and professional, still and moving image, text and sound become blurred.

There are of course existing generic precedents both within porn generally and gay porn specifically that popperbate videos can be related to. In the first instance many of the examples that I am referencing here are described as 'compilation videos' by their makers and compilations of unrelated shorts have been a staple of porn production since at least the VHS era. Additionally, during the 1980s and into the early 1990s major gay porn studios including Falcon, Catalina and His Video released preview tapes that consisted of a compilation of trailers for new releases and selected back catalogue features. These condensed versions of feature length videos, focussing on the highlights of each film were especially popular and trailers of course continue to be a key element of the marketing strategies of commercial gay porn producers. The videos that I have identified here though whilst they have a connection to the tradition of the compilation or the trailer are examples of something qualitatively different and in their own way can also be connected to an alternative arts practice of the found footage film, film collage or bricolage and I see this making practice as resulting in a hybridised gay porn version of this form. William Wees argues that the appropriation and repurposing of footage is key to this practice:

Found-footage filmmakers sift through the accumulated audio-visual detritus of modern culture in search of artefacts that will reveal more about their origins and uses than their original makers consciously intended. Then they bring their findings together in image-sound relationships that offer both aesthetic pleasure and the opportunity to interpret and evaluate old material in new ways.

(Wees, 2007, p.4)

And David Banash in a similar vein identifies the potential radicalism of this strategy:

The collage artist arranges fragments to which they have no holistic relationship through the labor of consumption. The process of assembling a collage more precisely mirrors the consumer wandering through a vast mall, selecting this and then that, bringing it all together in a new arrangement (that) reproduces the operations of the consumerist lifeworld. [...] Collage artists cut into images, syntax, and contexts, breaking things apart with the same radical zeal of Fordism.

(Banash, 2013:16/17)

What results from this practice is, I would argue, a form of gay pornographic bricolage. As Thomas Simonsen notes:

Bricolage describes the ability to make creative use of the materials made available from "whatever is at hand", and it is a "raw" or "naïve" art [...] The bricolage is concerned with a "science of the concrete". The concrete is the cultural texts of 
everyday life that are given new meaning in the bricolage. (2013:50)

I am mindful that drawing connections with popperbate videos and avant garde and experimental film making practice might perhaps be seen as elevating the status of this material or attributing to it a significance it does not deserve. However, I would counter this with the suggestion that, in a digital age marked by a visual and stylistic promiscuity, it's quite possible to see how aesthetics, tropes and techniques from the rarified domain of fine art (and of course routinely filtered for wider consumption via commercials and pop music videos) can be appropriated by the amateur film maker/pornographer/popperbater. What's especially interesting to me is that in popperbate videos this is a creative practice that results in instances of bricolage that makes no distinction between the provenance of the source material that is the raw footage for repurposing; commercial porn and webcam or phone footage, amateur video and still images, dance tracks with explicit lyrics and self-penned sex scenarios all become part of the same pool of data to create fantasies from. Whilst scholarly practice has striven to delineate the differences and distinctions between modes of amateur and professional production, these popperbate videos are examples of texts and a mode of production that, in the manner of the proliferation of gay blogs, Instagram and Tumblr sites, disregard those distinctions altogether and instead duplicate contemporary online conditions of consumption where browsing and clicking means that such distinctions are always blurred or contingent.

\section{The Popperbate Idiom: Scripting the Gay Male Porn Body}

The promiscuous collaging of a disparate range of source materials is a recurrent feature of almost all of the popperbate videos that circulate across the various content aggregator sites such as Xtube, Xvideos, or Pornhub. ${ }^{\mathrm{v}}$ Similarly, it's notable that a range of discursive registers are drawn on in these videos that are more widely recognisable across the practices of amateur video production online from Youtube to Xtube. I would argue that these discursive registers can be broadly be categorised as; the instructional ('how to' videos being the most straightforward example), the motivational (amateur exercise and fitness videos frequently adopt this register) and the therapeutic (amateur meditation videos for instance). What I am describing here as the popperbate idiom references all three of these modes in the service of establishing a reading position for the viewer/ participant in the popper training that will ensue and in scripting the sexual play on and offscreen.

Through reference to the language of the work-out or training session the timebound nature of the videos assumes an importance that it doesn't necessarily have in other modes of pornographic production in quite such an overdetermined way. Indeed, it often feels that the timebound nature of sexual play is central to the scripting of sexual activity that these videos are designed to facilitate. This can be played out around the urgency of sexual desire and the need for climax and release or the slow anticipation and build up to sexual play. The popperbate videos available at a range of tube sites tend to range from a minimum of 7 minutes as in the case of Cum Dumpster (Popper Hypno), vi a video that uses footage of a spinning hypnosis wheel, an ambient music soundtrack and a deep male voice instructing the viewer when to take a 'hit' of poppers before transitioning into a dance track and a montage of anal sex and cum shots. This specific video (as well as instances such as the especially 
imaginatively conceived and realised Poppers Machine Interactive Trainer ${ }^{\text {vii }}$ ) is an example that deviates from a fairly consistently established set of generic conventions that many of the sample of 20 popperbate videos analysed in the research for this essay demonstrate. At the other end of the temporal scale we can find examples of videos such as EXTREME Trainer w/ 20 Hit Challenge for Experienced PopperBators, ${ }^{\text {viii }}$ that at 37 minutes, use editing and frequent injunctions ('don't cum yet') to extend the time from arousal to climax. We can see in this diversity of practices a group of amateur producers experimenting with formats, styles and video lengths and the result of this has been the formalisation of a popperbate idiom.

Consequently, like much commercial porn the standard length for the majority of popperbate videos is between 15 and 20 minutes and an example such as Popper Trainer $1^{\text {ix }}$ that follows, almost to the letter, the format of the video that I cited at the start of this essay, indicative of an emergent popperbate idiom. Commencing with instructions for preparing for the training session that is to follow and a description of when and how to inhale poppers at key points, the video commences with a montage of still images of semi clad or naked male bodies and then following the first hit of poppers moves into an increasingly rapidly edited series of clips of action interspersing commercial and amateur footage. These videos tend to be posted on multiple sites, sometimes anonymously and sometimes not. On Xtube a poster called Marcotureno describes the content of this video as, "Popper training video featuring your standard gay stuff: bulges, cock rubbing, cocking sucking, rimming, fingering, fucking, bareback, and breeding" $\mathrm{x}$ and in so doing identifies the gay pornographic script that the majority of these videos construct. The popperbate idiom though is a sufficiently flexible structure to allow for some degree of formal and aesthetic experimentation and cross textual analysis of this burdgeoning area of amateur production demonstrates makers who use a range of creative techniques, through imitation of an established style, learning from and building on the generic blueprints established by others. ${ }^{\mathrm{xi}}$ For example, the relatively prosaic, though competently executed, videos of Xtube user Zachcartee follow the patterns established in the examples that I have discussed so far with the addition, as in Popper Training Triple Dose: The Second Cumming, of minor stylistic innovations such as motivational surtitles running along the bottom of the footage instructing viewers to "rub your hands over your chest and pecs!" and "jack off slowly and massage your chest!" xii Additionally, Zachcartee actively canvasses the feedback of the Xtube community via the usual route of online comments but this extends to the creation of a trailer for his third video in which, interspersed with sample clips of footage, he solicits feedback informing viewers that:

This is your chance to make requests for my third trainer video, tell me what you would like in the video, share your popperbating videos for inspiration, what do you think will take it to the next level? How many hits are you able to handle? How long

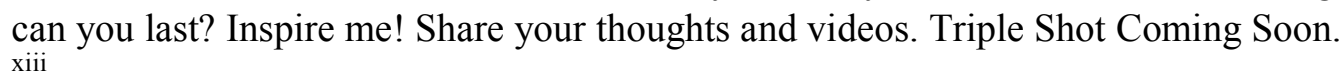

Whilst there are many examples of experimentation in form and style, in this emergent amateur making practice (it is notable that many popperbate videos include a date in their titling which suggests that this is a form of production that has escalated in the past 18 months) there are nonetheless a set of formal and rhetorical 'conventions' that manifest themselves to a greater of lesser degree across the majority of popperbate videos online. 
Firstly, and most prominently, the truncation of the gay pornographic narrative structure is a ubiquitous feature of these videos. A recurrent complaint made about commercial porn is that it is repetitive and boring and here we see explicit efforts to erase the longeurs popularly associated with this perennial critique of commercial output. ${ }^{\text {xiv }}$ So scenes of oral or anal sex are no longer extended edits of the same activity from various angles that all too often become relentless or encourage use of the fast-forward button. Instead, and on the contrary, popperbate video makers use rapid edits and a multiplication of a diversity of clips from scenes to create their video collage effects. This results, as in Poppers Trainer: Time Has $\mathrm{Cum}^{\mathrm{xv}}$ to striking sequences where multiple cum shots are edited into a 'medley' or, as in Poppers Experience: Massive Intense Orgasm, sequences where inserts of ejaculation from other scenes are edited into a cumshot to extend the length of the 'money shot', and presumably the intensity, of the effect. ${ }^{\text {xvi }}$

Secondly, and inevitably related to the editing strategies that popperbate video makers deploy, the use of music to create a coherent audio track and to provide a sense of tempo and a heightened sexual tone is a uniform feature of these videos. The music is almost always a dance track of the variety familiar to gym users (or indeed gay sex clubs) with an insistent and rapid beat. This choice of musical track, that is more than merely background accompaniment but is, in fact, key to establishing a mood, enables the popperbate video maker to script the unfolding sexual play on and offscreen and to establish an editing strategy. Drawing on the ambience of the music and clearly, in part, referencing the rapid edits of music video practices, clips and edited sequences are chosen to create tempo, excitement and anticipation. Paradoxically, anticipation often seen as absent in commercial narrative porn is built up by this sense of rapidity of editing across snippets of a range of sources and through the relentless drive of the music. The euphoric lift of the dance tracks at key moments are used as instances when viewers are encouraged to inhale poppers and finally at the end of the videos to ejaculate. ${ }^{\text {xvii }}$

Thirdly the overwhelming majority of popperbate videos draw on what might be regarded as the 'masculinist' discourses of sports, (Burstyn, 1999:28) competition and gaming to a greater or lesser degree and to a model of endurance training that is core to the practices of orgasm control (usually colloquially referred to as 'edging') that popperbate practice emerges from. ${ }^{\text {xviii }}$ This manifests itself in popperbate videos through the establishing sequences of the kind that have already been described and the scripted injunctions to inhale, to hold, to release, to 'keep going' and finally to cum. It is also frequently articulated through the construction of fantasy narratives that are scripted at text and inserted into the edits. For example, the Xtube user Bare Breeder who advises us his production practice has been inspired by the work of another user, MAXXX, suggesting a connoisseurship emerging around these videos, posts Popper Trainer: Jock Transformation (which confusingly also appears to be entitled Pig Transformation) on Xtube. ${ }^{\text {xix }}$ The video, regardless of any individuals' preference for 'pigs' over 'jocks', creates an overdetermined, albeit rather hackneyed, fantasy image of an imagined viewer (the text insistently addresses 'you') as a hyperpotent, hypersexual and hyperendowed 'straight' jock, firmly embedded in the manly world of sport, who submits to his suppressed desires and learns (very quickly it seems) to love gay sex. Accompanied by Maurice Joshua's Acid Trax opus of 1988, I Gotta Big Dick a dance track with a male vocal sample repeating the slogan of the songs title the text superimposed over a succession of still and then moving images encourages us to imagine that we are (or at least how it would feel to be) this epitome of a resolutely macho and yet sexually fluid, priapic modern man:

\section{Get your poppers and headphones ready}

If you can't make to the end KEEP TRAINING!

Growing up with a BIG DICK and a high sex drive was great 


\title{
3,2,1 Mandatory Hit
}

In high school you noticed everyone who was hot. Girls...

\author{
And...guys \\ You dated a few girls \\ You loved eating pussy \\ They loved your big dick inside them \\ And how you fucked them deep and for a long time...you're a STUD!! \\ College changed everything \\ You were so busy with sports and class you had no time for finding pussy \\ Sports let of some steam and you got ripped but still HORNY \\ You got boned when a team mate checked you out \\ He asked if he could help you out. You were cool with that \\ He surprised you and dropped to his knees to SUCK you off \\ Best HEAD ever \\ He asked you over. You were cool with more head. Ya'll had a few beers \\ You told him about loving to eat pussy and fucking for HOURS \\ He leaned over and started making out with you \\ Kissing a DUDE was way more fun than kissing chick \\ And he sucked your DICK again! \\ 3,2,1 Mandatory Hit
}

Considered en masse as a relatively recent example of contemporary amateur making practice what these videos reveal, obscure as they might be, through a combination of text, still and moving image and music is the production of a hybridised gay pornographic body.

Collectively popperbate videos are scripting the gay male porn body through rhetorical, stylistic and aesthetic strategies that strive via repetition and emphasis to summon up an essence of gay sexual desirability. It's perhaps axiomatic to emphasise here the primacy of the erect penis in videos designed as a stimulus for gay male masturbation practices for instance but examples such as Batetopia ${ }^{\mathrm{xx}}$ and Poppers Training ${ }^{x x i}$ make this abundantly and hyperbolically clear with cum shot after cum shot in succession. The rhetoric of the popperbate videos prioritises through editing and careful selection those aspects of the gay male body that matter within the context of popperbate play (and I think this process does indeed conflate the body into one body) and furthermore how, and in what sequence, to consume the gay male porn body. 
Perhaps what is most striking and paradoxical though about this scripting/construction of the gay male porn body is its heterogeneity. The videos both separately and collectively offer a kaleidoscopic range of masculine types for erotic consumption and they do this without creating a hierarchy of necessarily stereotypical desirability. So a perfectly groomed professional porn performer is presented alongside webcam footage of a skinny youth, alongside amateur footage of a hirsute and heavily built bear interspersed with male glamour photography and amateur mobile phone images. This mass of masculinity so saturated with sometimes conflicted meanings (Mercer, 2017) is offered to popperbate practitioners as aspects of one gay pornographic body that comprises a corporeality in constant movement and state of excitement; a pulsating, writhing body and a penis that is perpetually tumescent, glistening with saliva, dripping with prostatic fluid or erupting with ejaculate. In times of crisis and uncertainty elsewhere in the wider world these videos present a sexual script and a scripted gay male body where there is no uncertainty, no flaccidity, no failure or disappointment and no in between states.

\section{Final Thoughts}

Whilst this is an essay written as a contribution to a special edition exploring various articulations and critical approaches to analysing gay porn now (the 'nowness' being particularly important here) this 'now' has an air of déjà vu about it not least because so many popular anxieties and criticisms of porn, gay, straight or otherwise, seem perennial concerns. So whilst in the process of thinking critically about popperbate videos and the process of their creation and dissemination in this essay, I'm talking about a relatively 'new' phenomenon it's one that is situated in an all too recognisable social, cultural and political landscape of a broader concern about sex and sexuality, their relationship to pornography and its deleterious effects on society and this is worth reminding ourselves of in conclusion.

Even as we approach the second decade of the $21^{\text {st }}$ century much popular (and a disappointingly large proportion of critical work in the social sciences at least) is still predicated on assumptions about the unhealthy and harmful nature of porn. Indeed, it seems as if Laura Kipnis' rhetorical description of porn as "the sexuality of a consumer society" (1999:xii) has become the prevailing lens through which to read porn and one that is used (ironically given Kipnis' own argument that porn had social and cultural significance) to minimise the cultural significance or transgressive power of the form. That porn has no cultural merit or value beyond a very limited mechanical and instrumental sort is still in many quarters regarded as commonsensical. This instrumental value, of course, is as an aid to masturbation and as Thomas Bewley (2008: 36-37) notes the history of Western medicine going back further even than the $18^{\text {th }}$ Century has associated masturbation with illness and as essentially dangerous. Masturbation therefore has been regarded as by definition wasteful, self-indulgent and therefore bad and consequently material associated with the practice, in the case pornography, has the same associations.

Furthermore, even the most cursory survey of porn viewers online will reveal any number of individuals who decry the poor production standards, narrative flaws, lacklustre performances and various other demerits of commercial porn. The overarching critique being that commercial porn is generic, meaning that it is too repetitive, too mechanical, too contrived, too artificial, too banal; a mode of production in short that is perpetually 'failing' in some way. It's possible to argue that this supposed failing in part has provided the conditions for 
the rise of amateur porn production as a resulting congruence of audience demand and technological change. So what then can we say, as in the case of popperbate videos about porn made by amateurs responding expressly, emphatically and hyperbolically to what is seen as the utilitarian 'need' to have material to masturbate to? How can we conceptualise this instrumental motivation when it is elevated, through the vernacular creativity of amateurs, to such refined and exotic levels?

I'd like to conclude this essay by offering some potential avenues both for thinking about the specifics of popperbate videos but also, perhaps, the changing nature of porn consumption practices more widely. Firstly, as I noted at the start of this essay I think it's possible to situate this relatively new variant of gay porn within a wider context of neoliberalism and specifically the rationalization of leisure time that has become a prominent feature of contemporary popular culture. For example, in a recent essay Max Dawson has discussed the neoliberal logic that framed discourse around the emergence of Digital Video Recorders (DVR players) as a mechanism for a more effective and speedier consumption of television. He notes that the "DVR would 'rationalize' the act of watching television, making it a more efficient and/or productive leisure activity." (2014:223). This is a rubric that to some degree can extend itself to an understanding of popperbate videos which at their most functional can be rationalised as video collages designed for a swift and efficient way to consume large volumes of gay porn.

Additionally, Jean Burgess in her influential essay on vernacular creativity notes that:

The democratization of technologies discourse from the 'grassroots' converges persistently with emerging neoliberal business and economic models under which consumers (or 'users'), particularly of technology, are considered to possess and exercise more creativity and agency than before, combined with a surge in both the participation in and power of voluntary work and 'productive' leisure. (2006: 202)

Burgess' argument provides a context for a critique of popperbate video making practice which could be considered both as an example, as I have noted here, of vernacular creativity and also as evidence of the conjunction of leisure activity, sexual practice and technology marshalled into the production of 'productive leisure'. In this special edition Stephen Maddison connects his own assessment of the place of gay porn within gay culture to a wider set of developments in neoliberal politics. Importantly he notes that whilst to some degree gay men have benefitted from the social and cultural changes that neoliberalism brings about that it is also these very same set of circumstances that have collectively resulted in the erosion of a gay 'community'. Rather than gay men belonging to a wider constituency Maddison sees that we become atomised subjects/consumers. As Maddison himself notes the condition of the contemporary gay man (and the status of gay porn) is therefore a complex one:

One logical conclusion $[\ldots]$ is that contemporary gay men represent the very apex of neoliberal subjectivity: alienated, competitive, consumer-driven, privatized, fixated on localized experiences of erotic fulfillment, socially and economically privileged but disenfranchised. But the very currency of porn in gay culture, which has its roots in a relationship with sexually explicit imagery very different from the one we currently inhabit, may mean that gay men have been precisely best placed to resist the 
exploitation of immaterial sex, and have instead fostered subcultural conditions for using their cultural heritage and erotic investment in porn to manifest a 'comradeship of cock', in which social relations flourish in the face of neoliberal alienation.

(2017: In Press)

I would suggest following on from this line of argument that popperbate practice and popper training videos can very much be regarded as an example of the 'comradeship of cock' that Maddison looks for in a similar vein in blogging and Tumblr sites. In the midst of a neoliberal context of social alienation and via the mechanisms of 'productive leisure' is a form of amateur cultural production (videos made as gifts designed to be circulated amongst a community of shared interest) that certainly seems to be connect to a comradely principle.

Resonant as these readings might be, their essentialism cannot alone account for the seemingly organic emergence of this mode of pornographic expression and it's necessary therefore, I think, to look to conceptual models that try to countenance the specific conditions of online consumption. The way to do this of course is to be both mindful of political economy and cultural contexts of these videos and the making practices that they evidence but also to acknowledge their affective qualities. The relation between the conditions of consumption/reception of porn in the digital age is a topic that naturally enough a growing body of scholarship, largely initiated by the foundational work of Susanna Paasonen, has engaged with. In an essay written for this journal, Brandon Arroyo talks about the erratic and distracted nature of porn consumption online. He importantly notes:

the chaotic conditions of our present, which is often described as 'fast', 'impatient', and 'unsteady'; adjectives that evoke senses and feelings of movement. While studies of the covert networks facilitating the circulation of pornography have detailed porn' $\mathrm{s}$ intrinsic relationship to movement $[\ldots]$ less has been written about how contemporary viewers move through a multitude of texts, and what effects this has on porn consumption and erotic sensations. [...] what affects are triggered as a result of the continual scrolling and browsing through pornographic videos. What exactly are we looking for as we move from clip to clip? Is the aim just to find that perfect video to orgasm to, or is there potential eroticism lurking somewhere in the kinetic clicking from site to site?

(2016:308)

His astute analysis of this movement through the pornosphere provides an especially useful way to consider the workings and rhetorical strategies of popperbate videos. He concludes that, "Our constant clicking is less a sign of impatience than an expression of desire - a desire to find something beyond the text, to feel something that the text cannot give us." (2016:310)

These related ideas; impatience, a distracted sense of movement, the motivation to consume media output urgently, alongside the neoliberal logic of turning leisure (even masturbation) into a productive activity are ways that help us to think about the specifics of the sexual scripting that takes place in the popperbate videos but also to begin to imagine what the future of gay porn might become. 


\section{References}

Arroyo, B. (2016) 'From Flow to Float: Moving Through Porn Tube Sites.' Porn Studies, Vol. 3, No. 3, pp. 308-310.

Attwood, F. (2007) 'No Money Shot? Commerce, Pornography and New Sex Taste Cultures' Sexualities. Vol. 10 No. 4., pp. 441-456

Banash, D. (2013) Collage Culture: Readymades, Meaning, and the Age of Consumption. Amsterdam: Rodopi.

Bewley, T. (2008) Madness to Mental Illness: A History of the Royal College of Psychiatrists. London: The Royal College of Psychiatrists.

Burgess, J. (2006) 'Hearing Ordinary Voices: Cultural Studies, Vernacular Creativity and Digital Storytelling' Continuum: Journal of Media \& Culture Studies, Vol. 20, No. 2, pp. 201-214

Burstyn, V. (1999) The Rites of Men: Manhood, Politics, and the Culture of Sport. Toronto: University of Toronto Press.

Dawson, M. (2014) 'Rationalizing Television in the USA: Neoliberalism, the Attention Economy and the Digital Video Recorder' Screen Vol. 55. No. 2, pp.221-237

Escoffier, J. (2007) 'Scripting the Sex: Fantasy, Narrative and Sexual Scripts in Pornographic Film' in Kimmel, M. (ed) The Sexual Self: The Construction of Sexual Scripts. Nashville: Vanderbilt University Press.

Gelber, S. (1999) Hobbies: Leisure and the Culture of Work in America. New York: Columbia University Press.

Goffman, E. (1956) The Presentation of Self Everyday Life. Edinburgh: University of Edinburgh Press.

Hofer, K. (2014) 'Pornographic Domesticity: Amateur Couple Porn, Straight Subjectivities, and Sexual Labour' Porn Studies, Vol.1. No.4. pp. 334-345.

Jackson, R.L. (2006) Scripting the Black Masculine Body: Identity, Discourse, and Racial Politics in Popular Media. Albany, State University of New York.

Kipnis, L. (1999) Bound and Gagged: Pornography and the Politics of Fantasy in America. Durham: Duke University Press.

Maddison, S (2017) 'Comradeship of Cock? Gay Porn and the Entrepreneurial Voyeur' Porn Studies (in press)

Mercer, J. (2017) Gay Pornography: Representations of Masculinity and Sexuality. London: I.B.Tauris.

Paasonen, S. (2014) 'Things to do With the Alternative: Fragmentation and Distinction in Online Porn' in Biasin, E, Maina, G and Zecca, F (eds) Porn after Porn: Contemporary 
Alternative Pornographies. Udine: Mimesis Press.

MIT Press.

(2011) Carnal Resonance: Affect and Online Pornography. Cambridge MA:

(2010) 'Labors of Love: Netporn, Web 2.0 and the Meanings of

Amateurism.’ New Media \& Society, Vol.12, No.8, pp. 1297-1312.

Rosenberg, B. C. (2011) 'The Our House DIY Club: Amateurs, Leisure Knowledge and Lifestyle Media’ International Journal of Cultural Studies, Vol 14, No. 2, pp. 173-190.

Ruberg, B. (2016) 'Doing it for Free: Digital Labour and the Fantasy of Amateur Online Pornography’ Porn Studies, Vol.3. No.2. pp. 147-159.

Russo, J.L. (2009) 'User-Penetrated Content: Fan Video in the Age of Convergence.' Cinema Journal, Vol. 48, No. 4 (Summer, 2009), pp. 125-130

Simon, W., \& Gagnon, J. H. (1986). 'Sexual scripts: Permanence and Change' Archives of Sexual Behavior, Vol. 15, No. 2, pp. 97-119

New York: Aldine.

(1973). Sexual Conduct: The Social Sources of Human Sexuality.

Simonsen, T. (2013) 'The Mashups of You Tube' Nordicom Review Vol. 34 No. 2, pp. 47-63

Stebbins, R.A. (1992) Amateurs, Professionals, and Serious Leisure. Montreal: McGill University Press.

Tsika, N. (2016) 'Blue Transfusions: Internet Porn and the Pirating of Queer Cinema's Sex Scenes’ Porn Studies. Published online http://dx.doi.org/10.1080/23268743.2016.1174074

Van Doorn, N. (2010) 'Keeping it Real: User-Genderated Pornography, Gender Reification, and Visual Pleasure' Convergence, Vol. 16, no.4, pp. 411-30.

Wees, W. (2007) 'From, Compilation to Collage: The Found-Footage Films of Arthur Lipsett' Canadian Journal of Film Studies. Vol.14, No.22, pp.2-22.

Zecca, F. (2014) 'Porn Sweet Home: A Survey of Amateur Pornography' in Biasin, E, Maina, G and Zecca, F (eds) Porn after Porn: Contemporary Alternative Pornographies. Udine: Mimesis Press.

Notes:

i http://www.pornhub.com/view_video.php?viewkey=ph56f3bec18516d

ii See examples at:

http://www.xtube.com/video-watch/BareBreeder-Popper-Trainer-Getting-Trained-v2-25285182

http://www.xtube.com/video-watch/Poppers-Trainer-FSCRN-28118261

http://www.xtube.com/video-watch/Daddy-s-Popper-Training-28879261

URL: https://mc.manuscriptcentral.com/rprn E-mail: editorspstudies@gmail.com 
http://www.xtube.com/video-watch/POPPER-TRAINER-TRIPLE-DOSE-26340811

and discussion of popperbating practice and popperbate videos at:

http://fagsonlove.tumblr.com/

$\mathrm{https} / / / \mathrm{www}$. reddit.com/r/popperpigs/comments/4e $78 \mathrm{vt} / \mathrm{my}$ _favorite_popperbate_trainer_videos_for_now/ https://www.reddit.com/r/popperpigs/comments/3h450p/how_do_you_popperbate/

https://www.thumbzilla.com/gay/video/search?q=popper-bate

http://hottiebxl.tumblr.com/

iii See for example; http://www.xtube.com/video-watch/Popperbating-on-Cam-with-the-from-BW-20093962 and http://www.xtube.com/video-watch/Popperbating-to-Porn-12452151

iv There is perhaps a parallel albeit tenuous connection between the material that I discuss in this essays and repurposing of existing mainstream footage that Noah Tsika discusses in his essay 'Blue Transfusions: Internet Porn and the Pirating of Queer Cinema's Sex Scenes' for this special edition.

$\mathrm{v}$ It is naturally enough difficult to assess the number of popperbate/popper training videos in circulation. However, searches reveal that as of January 2017 well over 17,000 Xtube videos are tagged with the keywords 'popperbate' or 'popper training' (Xtube remaining the 'market leader' for amateur porn) with smaller number at Pornhub (1212) and Xvideos (325). Hundreds of Tumblr sites use popperbate/popperbator/popper training as titles and a search of Reddit yields over 5000 results. These searches disregard associated terms relating to masturbation practices such as 'edging', 'bating' or 'gooning' which produce even larger results but do not relate precisely to my object of study in this essay.

vi http://www.pornhub.com/view_video.php?viewkey=ph57d6a9d34393c

vii http://www.xtube.com/video-watch/Poppers-Machine-Interactive-trainer-19379712

viii

http://www.pornhub.com/view_video.php?viewkey=ph58344e2f4d8bd\&t=0\&utm_source=www.myvidster.com \&utm_medium $=$ embed\&utm_campaign $=$ embed-logo-html5

ix http://www.pornhub.com/view_video.php?viewkey=ph5696a93de64e9

x http://www.xtube.com/video-watch/Popper-trainer-compilation-for-popperbators-only-male-25990081

xi I would draw readers to this specific example that is less effective in it's execution and realisation in part at least because of the use of classical music as accompaniment. This seems to some extent at least to reference the history of gay pornographic cinema echoing the use of classical music in the films of Wakefield Poole. http://www.xtube.com/video-watch/21-salute-poppers-training-reload-25714791

xii http://www.xtube.com/video-watch/POPPER-TRAINER-The-Second-Cumming-26426911

xiii http://www.xtube.com/video-watch/POPPER-TRAINER-Triple-Shot-Trailer-27372281

xiv See online discussion of the various failings of commercial porn: https://www.reddit.com/r/AskReddit/comments/9qvto/have_you_become_bored_of_internet_porn/ https://www.reddit.com/r/AskMen/comments/1v0nrn/do_you_ever_get_tiredbored_with_porn_in_general/ http://sabotagetimes.com/sex/10-reasons-im-bored-porn https://www.datalounge.com/thread/12924565-why-isgay-porn-so-boring- http://www.justusboys.com/forum/threads/145465-Gay-porn-is-BORING

xv http://www.pornhub.com/view_video.php?viewkey=ph576871c90e411

xvi http://www.xtube.com/video-watch/Poppers-Experience-Massive-Intense-Orgasm-27393541

xvii There are many examples such as this: http://www.xtube.com/video-watch/Wank-the-Night-Away-PopperTraining-with-Binaural-Rhythms-29100481

xviii See http://www.xtube.com/video-watch/Poppers-Training-Interactive-Video-Extreme-Progressive26327481 and http://www.xtube.com/video-watch/Poppers-Experience-Massive-Intense-Orgasm-27393541 
xix http://www.xtube.com/video-watch/BareBreeder-Popper-Trainer-Jock-Transformation-24864691

xx http://www.xtube.com/video-watch/BATETOPIA-29382881

xxi http://www.pornhub.com/view_video.php?viewkey=ph56ed688d93118

10

11

12

13

14

15

16

17

18

19

20

21

22

23

24

25

26

27

28

29

30

31

32

33

34

35

36

37

38

39

40

41

42

43

44

45

46

47

48

49

50

51

52

53

54

55

56

57

58

59

60

URL: https://mc.manuscriptcentral.com/rprn E-mail: editorspstudies@gmail.com 